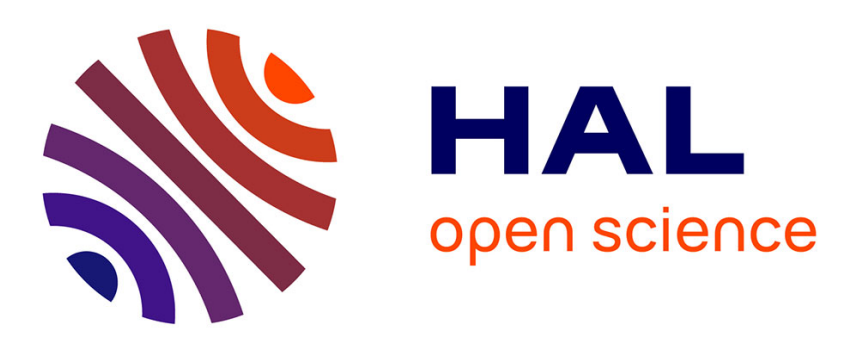

\title{
Large second order optical nonlinearity in thermally poled amorphous niobium borophosphate films
}

Marc Dussauze, Artem Malakho, Evelyne Fargin, Jean-Pierre Manaud, Vincent Rodriguez, Frédéric Adamietz, Bogdan Lazoryak

\section{To cite this version:}

Marc Dussauze, Artem Malakho, Evelyne Fargin, Jean-Pierre Manaud, Vincent Rodriguez, et al.. Large second order optical nonlinearity in thermally poled amorphous niobium borophosphate films. Journal of Applied Physics, 2006, 100 (1), pp.013108. 10.1063/1.2210572 . hal-00111943

\section{HAL Id: hal-00111943 \\ https://hal.science/hal-00111943}

Submitted on 3 Nov 2021

HAL is a multi-disciplinary open access archive for the deposit and dissemination of scientific research documents, whether they are published or not. The documents may come from teaching and research institutions in France or abroad, or from public or private research centers.
L'archive ouverte pluridisciplinaire $\mathbf{H A L}$, est destinée au dépôt et à la diffusion de documents scientifiques de niveau recherche, publiés ou non, émanant des établissements d'enseignement et de recherche français ou étrangers, des laboratoires publics ou privés. 


\title{
Large second order optical nonlinearity in thermally poled amorphous niobium borophosphate films
}

\author{
Marc Dussauze, Artem Malakho, Evelyne Fargin, ${ }^{\text {a) }}$ and Jean Pierre Manaud \\ Institut de Chimie de la Matière Condensée de Bordeaux, UPR 9048 CNRS, Chateau Brivazac, \\ Avenue du Dr. Schweitzer, 33608 Pessac Cedex, France \\ Vincent Rodriguez and Frederic Adamietz \\ Laboratoire de Physico-Chimie Moléculaire, UMR 5803 CNRS, Université Bordeaux I, \\ 351 cours de la Libération, 33405 Talence Cedex, France \\ Bogdan Lazoryak \\ Department of Chemistry, Moscow State University, Moscow, 119899, Russia
}

(Received 10 November 2005; accepted 28 April 2006; published online 11 July 2006)

\begin{abstract}
Thin films of sodium niobium borophosphate glass were deposited on silicon wafer and borosilicate glass substrates by radio frequency sputtering. Thermal poling of the films was performed under various voltage conditions. The chemical composition of the films after poling was controlled by $\mathrm{x}$-ray energy dispersive spectroscopy and compared to the initial composition. The second harmonic signals generated by thermal poling were analyzed in reflection mode. The recorded complex Maker fringes pattern signals were simulated and fitted using a multilayer model for the estimation of the second harmonic generation nonlinear coefficients $\chi^{(2)}$. The results are compared to previously published $\chi^{(2)}$ coefficients obtained for bulk oxide glasses $(\sim 3 \mathrm{pm} / \mathrm{V}$, approximately fourfold as strong as the highest value reported in thermally poled fused silica). Resulting from this study thermally poled niobium sodium borophosphate thin films are revealed of real interest as potential electro-optic devices. (C) 2006 American Institute of Physics. [DOI: 10.1063/1.2210572]
\end{abstract}

\section{INTRODUCTION}

Ferroelectric crystalline materials with high secondorder nonlinear optical (NLO) properties play an important role in optical communications. Single crystals and films made of ferroelectric compounds $\left(\mathrm{LiNbO}_{3}\right.$ and $\left.\mathrm{KTiOPO}_{4}\right)$ are extensively exploited as integrated electro-optic modulators and frequency converters. ${ }^{1}$ However, crystalline optoelectronic components have some disadvantages, such as limited size and shape, optical anisotropy, and appreciable cost of fabrication. In contrast, glasses are less expensive in fabrication, can be shaped in any form but they possess the inversion symmetry on a macroscopic scale, which precludes the occurrence of second order NLO processes, in the dipolar approximation. The glass centrosymmetry may be broken through a thermal poling process consisting in application of a high dc voltage at an elevated temperature $\left(\sim 200-400^{\circ} \mathrm{C}\right)$ and then cooling down the sample keeping the dc field on. ${ }^{2}$ As a result, an internal static electric field at the anode induces a second order nonlinear optical response in a layer with thickness ranging from 1 to $10 \mu \mathrm{m}$. The main origin of the observed second harmonic generation (SHG) signal arises from the interaction between the third order susceptibility $\chi^{(3)}$ of the glass and the internal electric field $E_{\text {int }}$ due to a depletion layer of cations at the anode side: ${ }^{2}$

$$
\chi^{(2)}=3 \chi^{(3)} E_{\text {int }} .
$$

Myers et al. were the first to produce a $\chi^{(2)}$ response of

\footnotetext{
${ }^{a)}$ Author to whom correspondence should be addressed; electronic mail: fargin@icmcb-bordeaux.cnrs.fr
}

$1 \mathrm{pm} / \mathrm{V}$ on thermally poled fused silica. ${ }^{2}$ After this pioneer work, glasses and glass ceramics with various compositions have been largely studied to improve the SHG efficiencies. Among the best results obtained until now for bulk glasses, $\chi^{(2)}$ coefficients ranging from 2 to $6 \mathrm{pm} / \mathrm{V}$ were reported for thermally poled $\mathrm{WO}_{3}-\mathrm{TeO}_{2}$ glasses, ${ }^{3}$ and more recently, $3-10 \mathrm{pm} / \mathrm{V}, \chi^{(2)}$ coefficients were observed in optically poled chalcogenide and sodium borophosphate glasses. ${ }^{4,5}$

Optical nonlinearity of poled amorphous thin films was largely studied and generally characterized by the SHG coefficient $\chi^{(2)}(-2 \omega, \omega, \omega)$. Although the waveguide electrooptic nonlinearity coefficient $\chi^{(2)}(-\omega, \omega, 0)$ is the interesting parameter for switching applications, SHG is considered as an efficient probe to compare glasses efficiencies. ${ }^{6}$ Thermally poled fused silica or more exotic borophosphate glasses thin films deposited by rf sputtering were successfully poled but they produce $\chi^{(2)}$ coefficients less than $1 \mathrm{pm} / \mathrm{V}$. ${ }^{7,8}$ Important improvement of the nonlinearity was obtained by doping the silica films with Ge. ${ }^{9}$ More recently, Luo et al. reported SHG cross-section measurements in a planar waveguide system after thermal poling. ${ }^{10}$ The system consisting in 0.05-0.2 $\mu \mathrm{m}$ thickness lead silicate glasses deposited on silica substrate and cladded with a $0.5 \mu \mathrm{m}$ thickness silica layer showed a large extrapolated $\chi^{(2)}$ up to $15 \mathrm{pm} / \mathrm{V}$ localized within the waveguide lead silicate glass layer. On the other hand, Quiquempois et al. studied the nonlinear optical coefficient profile in thermally poled thin silica glass samples putting forward the probable inefficiency of poling performed on thin samples with thickness in the same order of magnitude than the nonlinear layer width observed in the bulk glass. ${ }^{11}$ 
In this paper, we report elaboration, thermal poling, and SHG investigations of amorphous 3-7 $\mu \mathrm{m}$ thickness glass films with composition $(1-x)\left(0.95 \mathrm{NaPO}_{3}+0.05 \mathrm{Na}_{2} \mathrm{~B}_{4} \mathrm{O}_{7}\right)$ $+x \mathrm{Nb}_{2} \mathrm{O}_{5}, x=0.43$. Previous work on thermal poling of sodium niobium borophosphate bulk glasses of the same glass system $(x=0.4-0.5)$ allowed to produce reproducible $\chi^{(2)}$ coefficients up to $6 \mathrm{pm} / \mathrm{V}$ (quartz was used for calibration at $1064 \mathrm{~nm}$ with $\left.\chi^{(2)}=0.6 \mathrm{pm} / \mathrm{V}\right) .^{5}$ The aim in studying SHG in the thermally poled thin films was to reproduce in the films the record peak nonlinear coefficients previously obtained in the conductive bulk glasses. At the same time SHG measurements in reflection mode adapted to thin films characterization is set up and described, and the general model previously used for the bulk glass SHG simulations is proved to be efficient for this measurement configuration. ${ }^{12}$

\section{EXPERIMENT}

\section{A. Elaboration and characterization of the films}

Films were prepared by radio frequency (rf) sputtering. The sample of bulk glass $(50 \mathrm{~mm}$ in diameter and $3 \mathrm{~mm}$ thick), with composition $0.57\left(0.95 \mathrm{NaPO}_{3}+0.05 \mathrm{Na}_{2} \mathrm{~B}_{4} \mathrm{O}_{7}\right)$ $+0.43 \mathrm{Nb}_{2} \mathrm{O}_{5}$ was used as a target. Preparation of bulk glasses was described elsewhere. ${ }^{5}$ Depositions were performed at room temperature with a rf sputter power of $60 \mathrm{~W}$. The distance between the target and the substrate was $6 \mathrm{~cm}$, and the deposition rate was $16.3 \mathrm{~nm} / \mathrm{min}$. A mixture of argon $(97 \%)$ and oxygen $(3 \%)$ with a total pressure of $5 \times 10^{-6}$ bar was used during the deposition. Films with thicknesses of 3, 5, and $7 \mu \mathrm{m}$ were deposited on silicon (100) wafers ( $n$ doped). The thickness of each film was estimated with a profilometer.

An x-ray diffraction (XRD) study of the films was performed on a Philips Xpert powder diffractometer $\left(\mathrm{Cu} \mathrm{K}{ }_{\alpha}\right.$ radiation, $\theta-2 \theta$ geometry, reflection mode) at room temperature. The XRD analysis confirms the amorphous state of the films.

Scanning electron microscopy (SEM) experiments were performed by the use of a JEOL JSM 5510 microscope to control the surface quality of the films before and after poling.

Quantitative chemical compositions of the films were determined with a CAMECA electron probe x-ray wavelength dispersive spectrometer (WDS). $\mathrm{Na}, \mathrm{Nb}$, and $\mathrm{P}$ concentrations were measured for three to five points on each sample and averaged. Line scan measurements with step $0.5 \mu \mathrm{m}$ were made on the cross section of thermally poled $5 \mu \mathrm{m}$ film deposited on silicon wafer.

One of the prepared films was deposited on a substrate made of borosilicate glass (Schott D263) in order to record its optical transmission spectrum. The spectrum was collected on a CARY (Varian) spectrometer in the wavelength range of 200-3000 $\mathrm{nm}$. A borosilicate glass plate identical to the substrate was used for baseline correction.

The linear refraction indices of the films deposited on (100) silicon wafers were measured at 1064 and $532 \mathrm{~nm}$, using the Brewster angle reflection method over the $\pm\left[10^{\circ}, 80^{\circ}\right]$ wide $\theta$ range.

Raman spectra of the films were recorded with a Labram confocal micro-Raman instrument (Horiba-Jobin Yvon) in

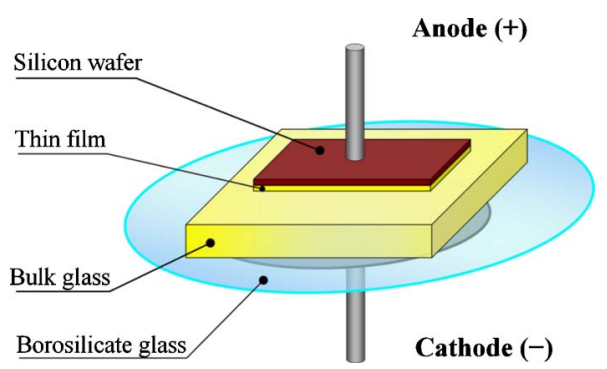

FIG. 1. (Color online) Scheme of the thermal poling configuration for a film deposited on a silicon wafer.

the backscattering geometry at room temperature, with a typical resolution of $3 \mathrm{~cm}^{-1}$. The spectrophotometer includes a holographic Notch filter for Rayleigh rejection, a microscope equipped with $\times 100$ objective, and a charge-coupled device (CCD) detector. The $514.5 \mathrm{~nm}$ emission line of an argon ion laser was used for excitation.

\section{B. Thermal poling and SHG measurements}

Thermal poling of the glass films deposited on silicon wafers was done under air at normal pressure. The silicon wafer was used as the anode electrode. Additional bulk glass plates were introduced in between the electrodes in order to ensure a comparable poling configuration to that we successfully used in bulk glasses (Fig. 1). ${ }^{5}$ A first additional $600 \mu \mathrm{m}$ thick bulk glass plate with the same composition as the target used for thin film deposition was placed as a buffer underneath the film. An additional $110 \mu \mathrm{m}$ thick borosilicate bulk glass plate was placed under the previous one at the cathode side in contact with the stainless steel cathode. Applied dc voltages were, respectively, $0.75,1,1.5$, and $2 \mathrm{kV}$ and the poling temperature was $230^{\circ} \mathrm{C}$. Each sample was heated at $230{ }^{\circ} \mathrm{C}$ for at least one $1 \mathrm{~h}$ before applying the electric field during $30 \mathrm{~min}$ and then cooled down to room temperature before removing the dc bias.

Second harmonic measurements in reflection mode were performed on poled films deposited on silicon wafer. The light source was a $Q$-switched YAG:Nd (YAG denotes yttrium aluminum garnett) laser operating at a wavelength of $1064 \mathrm{~nm}$, with a pulse width of $30 \mathrm{~ns}$ at a repetition rate of $30 \mathrm{~Hz}$. The $\mathrm{TEM}_{00}$ Gaussian polarized source beam was split into two rays by a beam splitter. One branch recorded the fundamental intensity with a near infrared photodiode; the other one, linearly polarized, was focused onto a rotating sample $(\theta)$ with a Gaussian beam waist circum ference of $80 \mu \mathrm{m}$. The $2 \omega$ reflected signal, averaged over $\sim 50$ pulses, was detected by a Hamamatsu compact photomultiplier unit disposed onto an angular $\theta-2 \theta$ goniometer. Absolute values of the second order susceptibilities were obtained using a quartz z-cut plate, taking $\chi_{111}^{(2)}=0.6 \mathrm{pm} / \mathrm{V}$ as a reference for the calibration of the SHG setup. ${ }^{1}$ Polarized p-p and s-p Maker fringe patterns in reflection were recorded and simulated for the studied samples. A general $4(n+1) \times 4(n+1)$ matrix formulation of linear and nonlinear optical responses, described previously by one of us, ${ }^{12}$ has been used here to simulate both the reflected fundamental (Brewster patterns) and harmonic waves (Maker fringes patterns) through the 
TABLE I. Chemical compositions analysis of a film deposited on a silicon wafer compared to the target glass before and after deposition. The error in the atomic composition estimation is typically $0.1 \%-0.2 \%$.

\begin{tabular}{ccccc}
\hline \hline Sample & $\begin{array}{c}\mathrm{Na} \\
\text { (at. \%) }\end{array}$ & $\begin{array}{c}\mathrm{Nb} \\
(\text { at. \%) }\end{array}$ & $\begin{array}{c}\mathrm{P} \\
(\text { at. \%) }\end{array}$ & $\begin{array}{c}\mathrm{O} \\
(\text { at. \%) }\end{array}$ \\
\hline $\begin{array}{c}\text { Film on silicon substrate } \\
\text { Target glass }\end{array}$ & 8.3 & 17.6 & 7.4 & 66.7 \\
Target after deposition & 11.2 & 15.4 & 8.4 & 65.0 \\
Theoretical composition of target & & & \\
Then & 10.3 & 14.8 & 7.7 & 63.4 \\
\hline \hline
\end{tabular}

${ }^{\mathrm{a}}$ Theoretical compositions are rescaled to $100 \%$, considering that boron content was not quantified. Oxygen at. \% is then calculated to ensure the stoiechiometry.

glass film/silicon wafer bilayer. This formulation is applicable to any isotropic/anisotropic material containing $n$ layers, and it is convenient and straightforward for experimental data analyses. All complementary details about the experimental setup and the general multilayer propagation model used for simulations allowing to extract $\chi^{(2)}$ coefficients and nonlinear zone thickness for each nonlinear layer can be found elsewhere. ${ }^{12}$

\section{RESULTS}

\section{A. Thin films characterizations}

Chemical compositions of films and target glass are given in the Table I. The compositions are close together although the concentration of sodium in the film appears substantively lower. The films are transparent in the $400-2000 \mathrm{~nm}$ range. The reduced $300-900 \mathrm{~nm}$ absorption spectrum of a $5 \mu \mathrm{m}$ thick film (Fig. 2) reveals nice interference pattern correlated to the thickness of the glass film. The linear optical Brewster patterns of the films (Fig. 3) are highly perturbated by the interferences due to the thickness of the glass film and also due to the dielectric contrast with the Si wafer. Accurate thicknesses and refraction indices obtained from the best fit of the experimental curves are summarized in Table II.

Figure 4 shows the Raman spectrum of a $5 \mu \mathrm{m}$ thick film deposited on a silicon substrate. The Raman spectra of bulk glasses $(1-x)\left(0.95 \mathrm{NaPO}_{3}+0.05 \mathrm{Na}_{2} \mathrm{~B}_{4} \mathrm{O}_{7}\right)+x \mathrm{Nb}_{2} \mathrm{O}_{5}$ for $x=0.40,0.43$, and 0.48 are given for comparison. An assignment of the different vibration modes is proposed following Lipovskii et al. ${ }^{13}$ and Cardinal et al. ${ }^{14}$ Two main bands for

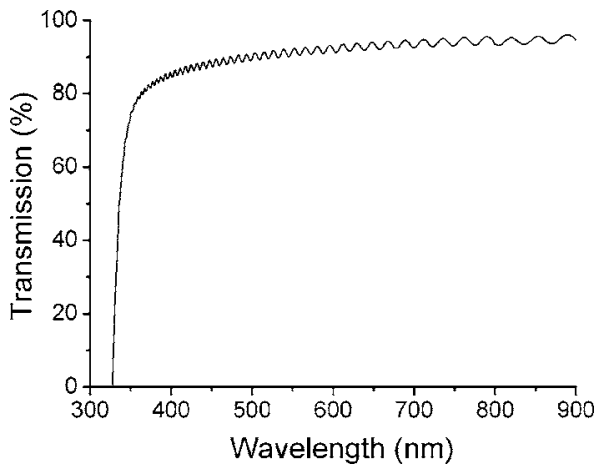

FIG. 2. Optical transmission spectrum of unpoled glass film (thickness $5 \mu \mathrm{m})$ deposited on a borosilicate glass plate.
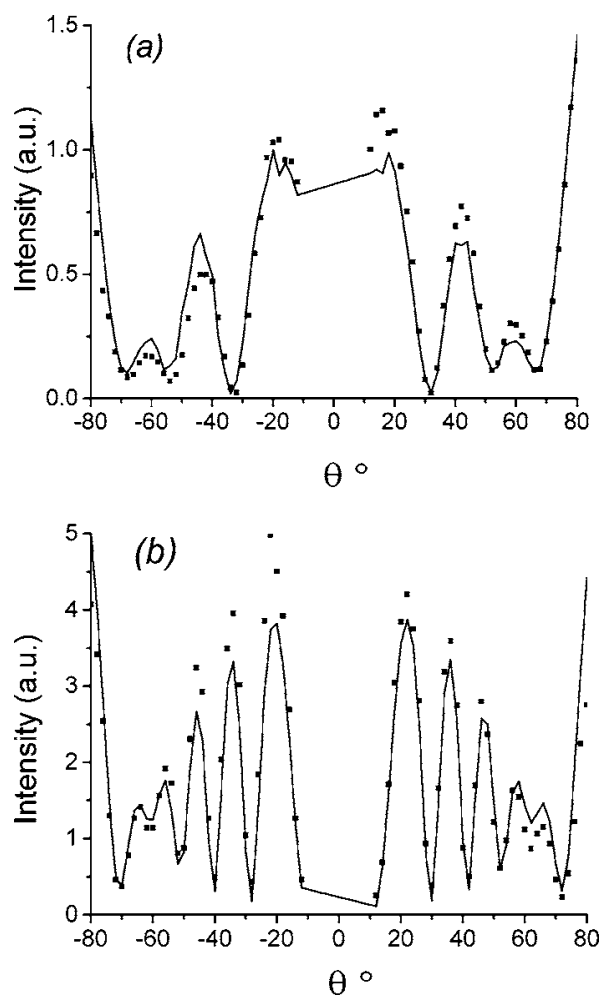

FIG. 3. Experimental (points) and calculated (solid lines) Brewster angle reflection patterns of film (thickness $5 \mu \mathrm{m}$ ) deposited on silicon wafer at $1064 \mathrm{~nm}$ (a) and $532 \mathrm{~nm}$ (b).

the film at 680 and $780 \mathrm{~cm}^{-1}$ can be, respectively, attributed to the vibrations of $\mathrm{Nb}-\mathrm{O}-\mathrm{Nb}$ bridging bonds in three dimensional (3D) niobium oxygen framework and $\mathrm{Nb}-\mathrm{O}-\mathrm{P}$ or $\mathrm{Nb}-\mathrm{O}-\mathrm{Nb}$ bonds in one dimensional (1D) or two dimensional (2D) niobate or phosphoniobate semicovalent framework. Less intensive and very wide bands at $1000-1200 \mathrm{~cm}^{-1}$ are attributed to the vibration of isolated phosphate $\left(\mathrm{PO}_{4}\right)^{3-}$ entities and terminal- $\left(\mathrm{PO}_{3}\right)^{2-}$ groups in phosphate chains. The band at $860-1000 \mathrm{~cm}^{-1}$ which is observed for bulk glasses and attributed to $\mathrm{Nb}-\mathrm{O}^{-} \cdots \mathrm{Na}^{+}$ionic bonds vibrations is overlapped by the silicon substrate vibration band. The intensity ratios of the observed bands are identical for the thin film and bulk glass with the same composition. One may conclude that niobium is mainly forming a 3D network as it was previously shown for bulk glass. ${ }^{14}$

\section{B. Poled thin films characterizations}

Electron microscopy was used to check the surface quality of the poled films as a function of the applied dc field.

TABLE II. Refraction indices and nonlinear optical susceptibilities $\chi^{(2)}$ deduced from linear and nonlinear optical analyses of the reflected patterns for thermally poled glass films. The absorption coefficient is defined as $\alpha$ $=2 \pi k / \lambda ; n$ and $k$ are, respectively, the real and imaginary parts of the complex refraction index.

\begin{tabular}{|c|c|c|c|c|c|}
\hline & $\begin{array}{c}n_{1064 \mathrm{~nm}} \\
\pm 0.01\end{array}$ & $\begin{array}{l}n_{532 \mathrm{~nm}} \\
\pm 0.01\end{array}$ & $\begin{array}{c}\alpha_{1064 \mathrm{~nm}} \\
\left(\mathrm{~cm}^{-1}\right) \\
\pm 0.1\end{array}$ & $\begin{array}{c}\alpha_{532 \mathrm{~nm}} \\
\left(\mathrm{~cm}^{-1}\right) \\
\pm 10\end{array}$ & $\begin{array}{c}\left\langle\chi^{(2)}\right\rangle \\
(\mathrm{pm} / \mathrm{V}) \pm 0.1\end{array}$ \\
\hline Si wafer & 3.51 & 4.26 & 82.2 & 2300 & $\cdots$ \\
\hline Film $3 \mu \mathrm{m}$ & 1.83 & 1.90 & $\cdots$ & $\ldots$ & 3.0 \\
\hline Film $5 \mu \mathrm{m}$ & 1.83 & 1.90 & $\cdots$ & $\cdots$ & 2.9 \\
\hline Film $7 \mu \mathrm{m}$ & 1.82 & 1.92 & $\cdots$ & $\cdots$ & 3.2 \\
\hline
\end{tabular}




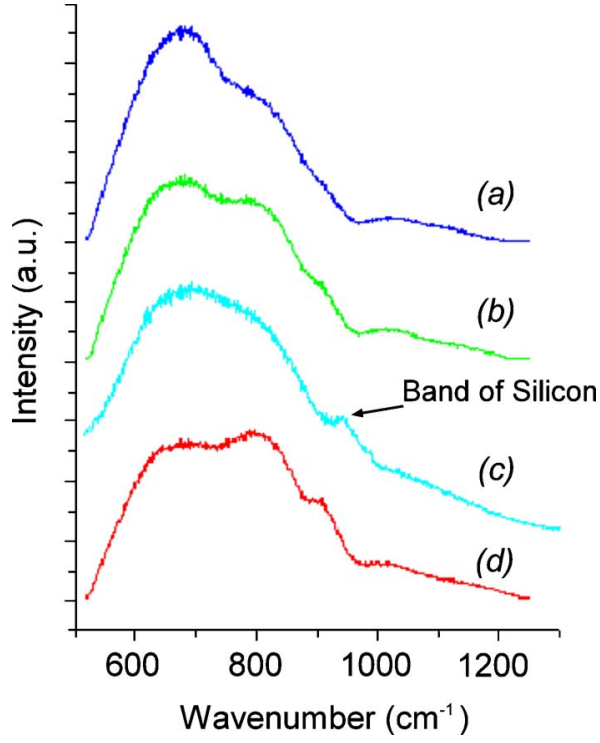

FIG. 4. (Color online) Raman spectrum of a glass film (thickness $5 \mu \mathrm{m}$ ) deposited on a silicon wafer (c) compared to Raman spectra of as-prepared glasses from the same glass system with $x=48$ (a), $x=43$ (b), and $x=40$ (d)

Figure 5 shows the SEM images obtained for a film surface before and after a poling treatment under $1.5 \mathrm{kV}$. The surface quality of the film is preserved after poling but one can notice the occurrence of a few holes attributed to local electrical breakdown. These effects of charge disrupting dramatically increase under more drastic $2 \mathrm{kV}$ applied voltage. Large inhomogeneous areas are observed on Fig. 6. The elemental analysis performed on different parts of the poled film shows the following: (i) on the dark area, an accumulation of sodium compared to the concentration before poling (Table I); (ii) on the light area, a departure of sodium. Sodium ions are effectively supposed to migrate during the poling treatment inducing a gradient of concentration in the film which should generate an embedded internal static electric field $E_{\text {int }}$ [see Eq. (1)]. In the case of films poled under dras-

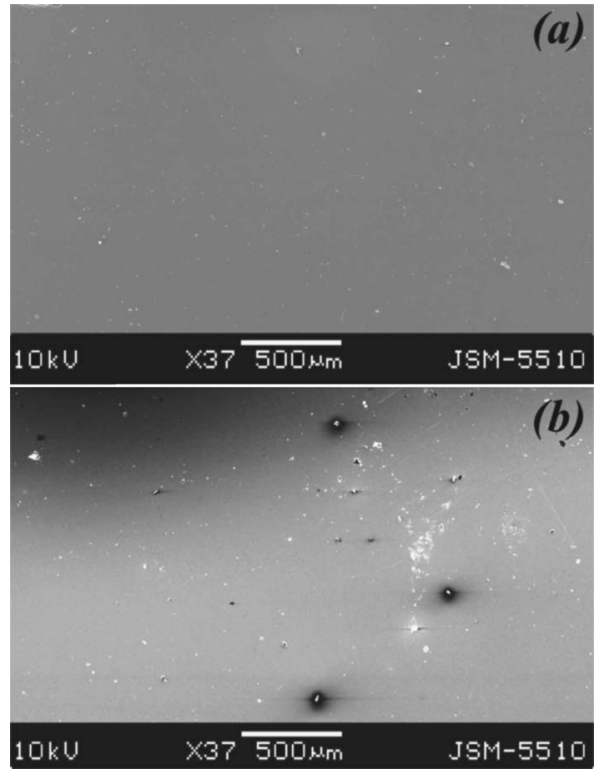

FIG. 5. SEM images of a film (thickness $7 \mu \mathrm{m}$ ) deposited on a silicon wafer before (a) and after (b) a thermal poling treatment $\left(1.5 \mathrm{kV}, 30 \mathrm{mn}, 230^{\circ} \mathrm{C}\right)$.

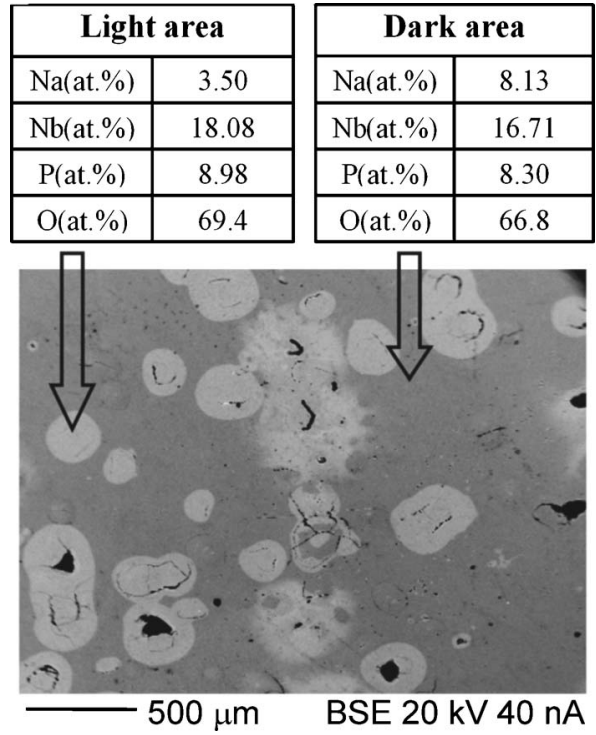

FIG. 6. Back scattering electron image of a film (thickness $7 \mu \mathrm{m}$ ) on a silicon wafer after a thermal poling treatment $\left(2 \mathrm{kV}, 30 \mathrm{mn}, 230{ }^{\circ} \mathrm{C}\right)$. Table insets on the right side report atomic compositions measured by WDS

tic $2 \mathrm{kV}$ the migration of sodium ions from the film surface to the bulk glass buffer may be massive leading to the destruction of the film surface.

Figure 7 shows normalized p-p polarized SHG reflected patterns for films after poling given for $1,1.5$, and $2 \mathrm{kV}$ for comparison. One can see that films poled under $1.5 \mathrm{kV}$ external voltage show the most intensive SHG signal. SHG efficiency after poling with $2 \mathrm{kV}$ is less than that of the poling with $1.5 \mathrm{kV}$, which may be a result of this destructive electric breakdown effect on the surface optical quality. To conserve the homogeneity and surface quality of poled films, it is necessary to limit the surface electric field responsible for the depletion in cations (as described in theoretical models). ${ }^{15,16}$ The value of external field should be small enough to avoid intensive transfer of $\mathrm{Na}^{+}$between the film and the bulk glass.

Full SHG analysis was performed on 3, 5, and $7 \mu \mathrm{m}$ thickness films poled under $1.5 \mathrm{kV}$ at $230{ }^{\circ} \mathrm{C}$ and during

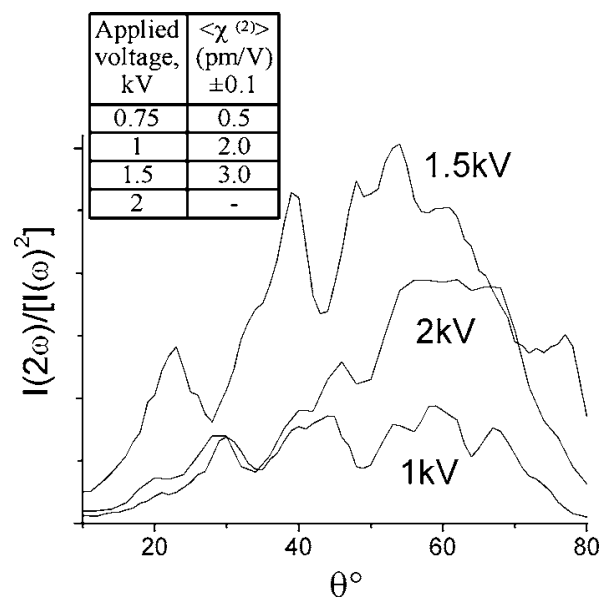

FIG. 7. Experimental reflected p-p SHG Maker-fringe patterns of glass films (thickness $5 \mu \mathrm{m}$ ) on a silicon wafer, poled during $30 \mathrm{~min}$ at $230^{\circ} \mathrm{C}$ given for $1,1.5$, and $2 \mathrm{kV}$. Table inset shows estimated nonlinear optical susceptibilities $\chi^{(2)}$ for glass films thermally poled with different voltages. 

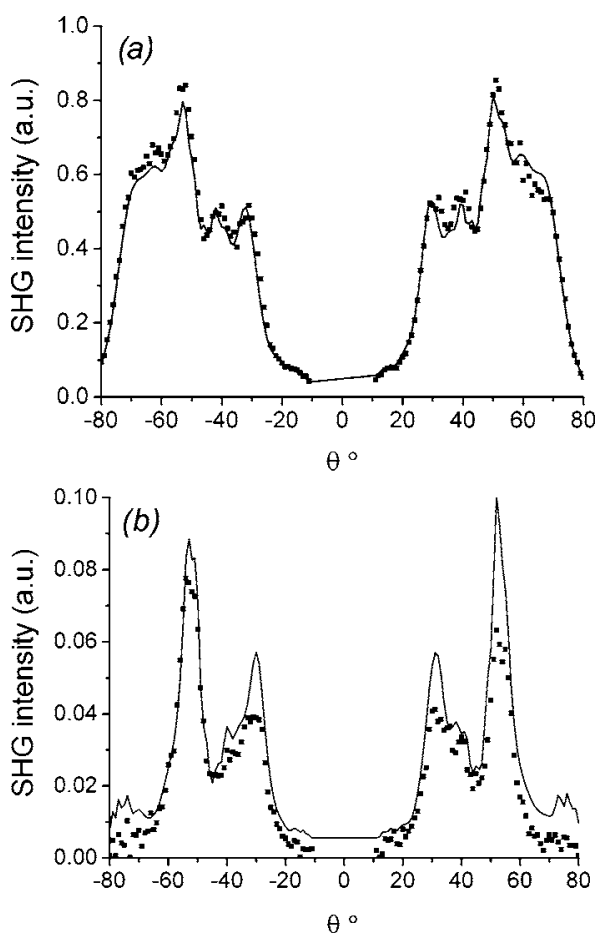

FIG. 8. Experimental (points) and calculated (solid lines) reflected p-p (a) and s-p (b) polarized SHG Maker-fringe patterns of a glass film (thickness $5 \mu \mathrm{m}$ ) deposited on silicon wafer, poled during $30 \mathrm{~min}$ at $230{ }^{\circ} \mathrm{C}$ with $1.5 \mathrm{kV}$.

30 min, which are the nominal poling temperature and duration used for bulk glasses with the same composition. ${ }^{17}$ Linear and nonlinear reflected patterns were simulated and fitted with a unique multilayer optical propagative model, considering the refractive indices of the silicon wafer layer (Figs. 3 and 8 ). The following assumptions were made to simplify the simulations.

- Second order NLO susceptibility $\chi^{(2)}$ appears due to the interaction of $\chi^{(3)}$ with the internal electric field $E_{\text {int }}$ [see Eq. (1)], therefore $\chi^{(2)}=3 \chi^{(3)} E_{\text {int }}$.

- The NLO layer is homogeneously generated within the whole film.

The experimental and calculated reflected SHG patterns for a $5 \mu \mathrm{m}$ thick sample are shown in Fig. 8. Fitted values of refractive indices and nonlinear optical susceptibilities are given in Table II. Films with different thicknesses show similar NLO $\chi^{(2)}$ coefficients close to the $\chi^{(2)}=3 \mathrm{pm} / \mathrm{V}$ previously obtained for the same composition bulk glass. ${ }^{17}$

\section{DISCUSSION}

As it was previously shown, the progressive formation of a 3D niobate framework in the bulk compositions when increasing the concentration of niobium plays major role in improving the third order NLO $\chi^{(3)}$ efficiency (Fig. 4). ${ }^{14}$ As a consequence the SHG response induced by thermal poling in the bulk $0.57\left(0.95 \mathrm{NaPO}_{3}+0.05 \mathrm{Na}_{2} \mathrm{~B}_{4} \mathrm{O}_{7}\right)+0.43 \mathrm{Nb}_{2} \mathrm{O}_{5}$ composition was obtained up to $3 \mathrm{pm} / \mathrm{V}$., ${ }^{5,17}$ The deposition was first successfully obtained and the Raman spectroscopy evidenced comparable local structure in bulk and thin film glass. This was encouraging to expect future generated sec-

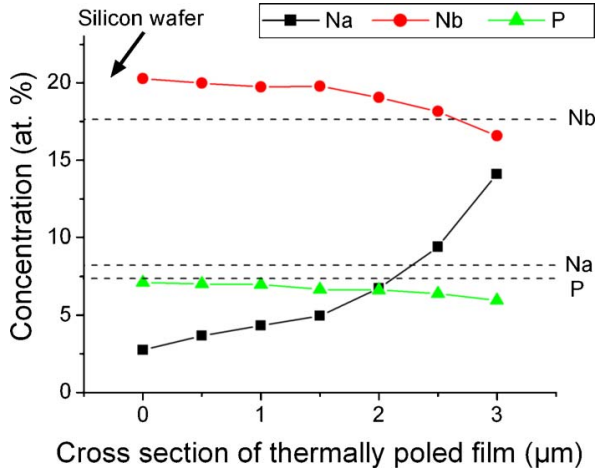

FIG. 9. (Color online) Chemical composition analysis of cross section for thermally poled film (thickness $5 \mu \mathrm{m}$ ) deposited on silicon wafer. First and last points of scan were omitted because they have strong influence on the surface effect. Dashed lines show atomic concentration of $\mathrm{Na}, \mathrm{Nb}$, and $\mathrm{P}$ in nonpoled film. The error in the atomic composition estimation is typically $0.1 \%-0.2 \%$.

ond order NLO coefficients in the film, the $\chi^{(3)}$ value being supposed to be as high as in the bulk though it has not yet been measured.

The challenge was then to adapt the poling process to thin films in view of reproducing the large NLO efficiency of the poled bulk glass. This was obtained by the use of a bulk glass buffer with the same composition sandwiched between the film and a borosilicate glass plate. The departure of sodium from the film to the surface in contact with the buffer was demonstrated by WDS elemental analysis. This analysis was performed on the cross section from the silicon substrate to the surface of the poled film, and the results are given on Fig. 9. A depletion of sodium is observed near the surface in contact with the silicon wafer (anode), and the sodium concentration is progressively increasing from this point to the external surface. This allows supposing a migration model of sodium ions as it was done for the bulk glass. ${ }^{17}$

As a matter of fact the generated NLO $\chi^{(2)}$ coefficients are comparable for films and bulk glass. Second order optical nonlinearity is distributed throughout the few micrometer thicknesses either in the film or in the anodic layer of the bulk glass. However, the correlations between the estimated $\chi^{(2)}$ coefficients and the applied voltage values for a given film thickness, temperature, and poling duration (Fig. 7) are not still explained. A constant nonlinear efficiency was observed for the bulk, abruptly disappearing when the voltage is lower than $1 \mathrm{kV}$, the existence of a threshold voltage was assumed following the model proposed by Quiquempois et al. for fused silica. ${ }^{5,15}$ In the films, the nonlinearity is progressively decreasing from 1.5 to $0.75 \mathrm{kV}$, and a threshold voltage could not be evidenced.

\section{CONCLUSION}

This article describes a method for thermal poling of sodium borophosphate niobium glass films deposited on silicon wafers. A strong influence of the external applied voltage on the poled films quality was observed, and the voltage value was selected for optimization of the NLO efficiency avoiding destruction of the poled film surface. The $\chi^{(2)}$ value has been measured using a setup of reflected Maker fringes 
recording and adapted simulation. A reproducible $3 \mathrm{pm} / \mathrm{V}$ $\chi^{(2)}$ coefficient (five times the quartz response) was obtained independently to the 3-7 $\mu \mathrm{m}$ thicknesses of the films. This encouraging result is in favor of developing thin films of glasses with large sodium concentration for future waveguide applications. Application of these materials could help to overcome limitations previously mentioned for silica glass. ${ }^{11}$

\section{ACKNOWLEDGMENTS}

The authors acknowledge the ACI nanosciencesnanotechnologies program for financial support. One of the authors (A.M.) is grateful to the French government for the scholarship. Another author (V.R.) is indebted to the Région Aquitaine for financial support in optical, laser, and computer equipment. The authors are thankful to Dr. V. A. Morozov and Professor G. Van Tendeloo for SEM experiments.

${ }^{1}$ V. G. Dmitriev, G. G. Gurzadyan, and D. N. Nikogosyan, Handbook of Nonlinear Optical Crystals (Springer, Berlin, 1991).

${ }^{2}$ R. A. Myers, N. Mukherjee, and S. R. J. Brueck, Opt. Lett. 16, 1732 (1991).

${ }^{3}$ K. Tanaka, A. Narazaki, and K. Hirao, Opt. Lett. 25, 251 (2000).
${ }^{4}$ M. Guignard, V. Nazabal, J. Troles, F. Smektala, H. Zeghlache, Y. Quiquempois, A. Kudlinski, and G. Martinelli, Opt. Express 13, 789 (2005).

${ }^{5}$ M. Dussauze, E. Fargin, M. Lahaye, V. Rodriguez, and F. Adamietz, Opt. Express 13, 4064 (2005).

${ }^{6}$ M. G. Kuzik and C. W. Dirk, Characterization Techniques and Tabulations for Organic Nonlinear Optical Materials (Marcel Dekker, New York, 1998).

${ }^{7}$ S. Horinouchi, H. Imai, G. J. Zhang, K. Mito, and K. Sasaki, Appl. Phys. Lett. 68, 3552 (1996).

${ }^{8}$ B. Ferreira, E. Fargin, J. P. Manaud, G. Le Flem, V. Rodriguez, and T. Buffeteau, J. Non-Cryst. Solids 242, 16 (1998).

${ }^{9}$ A. Ozcan, M. J. F. Digonnet, G. S. Kino, F. Ay, and A. Aydinli, Opt. Express 12, 4698 (2004).

${ }^{10}$ Y. Luo, A. Biswas, A. Frauenglass, and S. R. J. Brueck, Appl. Phys. Lett. 84, 4935 (2004)

${ }^{11}$ Y. Quiquempois, A. Kudlinski, and G. Martinelli, J. Opt. Soc. Am. B 22, 598 (2005).

${ }^{12}$ V. Rodriguez and C. Sourisseau, J. Opt. Soc. Am. B 19, 2650 (2002).

${ }^{13}$ A. A. Lipovskii, D. K. Tagantsev, A. A. Vetrov, and O. V. Yanush, Opt. Mater. (Amsterdam, Neth.) 21, 749 (2003).

${ }^{14}$ T. Cardinal, E. Fargin, G. Le Flem, and S. Leboiteux, J. Non-Cryst. Solids 222, 228 (1997).

${ }^{15}$ Y. Quiquempois, N. Godbout, and S. Lacroix, Phys. Rev. A 65, 043816 (2002).

${ }^{16}$ N. Godbout and S. Lacroix, J. Non-Cryst. Solids 316, 338 (2003).

${ }^{17}$ M. Dussauze, E. Fargin, A. Malakho, V. Rodriguez, T. Buffeteau, and F. Adamietz, Opt. Mater. (Amsterdam, Neth.) (in press). 